\title{
The high amino-acid content of sputum from cystic fibrosis patients promotes growth of auxotrophic Pseudomonas aeruginosa
}

\author{
A. L. BARTH and T. L. PITT \\ Laboratory of Hospital Infection, Central Public Health Laboratory, 61 Colindale Avenue, London NW9 5HT
}

\begin{abstract}
Many isolates of Pseudomonas aeruginosa from cystic fibrosis (CF) patients are auxotrophic and require amino acids for growth. A quantitative assay was used to determine the total content of free amino acids of sputum sol-phase extracts from $\mathrm{CF}$ and non-CF patients to assess the presence of amino acids in the airway. CF patients colonised with auxotrophic $P$. aeruginosa had a higher sputum amino-acid content (mean $6.77 \mathrm{mg} / \mathrm{ml}$ ) than those colonised with prototrophs (mean $3.77 \mathrm{mg} / \mathrm{ml}$ ); overall, CF specimens (mean $5.70 \mathrm{mg} / \mathrm{ml}$ ) had a higher amino-acid content than non-CF samples $(2.52 \mathrm{mg} / \mathrm{ml})$. The amino-acid profile of sputum extracts was assessed by onedimensional thin layer chromatography (TLC). Several amino acids were identified in the extracts, in particular, leucine, isoleucine, phenylalanine, tyrosine, alanine, serine and methionine or valine or both. All sputum specimens except two (which contained $<1.5 \mathrm{mg}$ of amino acids $/ \mathrm{ml}$ ), promoted the growth, of 34 auxotrophic strains of $P$. aeruginosa from CF patients in a minimal medium. These results indicate, therefore, that amino acids are plentiful in the sputum of CF patients and are able to supply the requirements of auxotrophic strains. It is suggested that the increased amino-acid content in the airways of $C F$ patients plays a significant role in the selection and maintenance of nutritionally deficient $P$. aeruginosa.
\end{abstract}

\section{Introduction}

Deterioration of lung function in patients with cystic fibrosis (CF) is one of the major determinants of the high morbidity and mortality associated with the disease [1]. The airways of CF patients are invariably colonised by Pseudomonas aeruginosa which, during the course of the disease, undergoes many phenotypic variations. Production of alginate exopolysaccharide [2], sensitivity to human serum [3], hypersensitivity to semi-synthetic penicillins [4] and other phenotypic alterations appear to be a result of the adaptation of the bacterium to the environment in the CF lung. This adaptability extends to the nutritional status of the organism with many strains of $P$. aeruginosa from $\mathrm{CF}$ exhibiting auxotrophy for amino acids [5]. These variants are derived, in the lung, from prototrophic nutritionally efficient wild-type strains [6].

The physical and chemical properties of the CF

Received 9 Aug. 1995; revised version accepted 19 Jan. 1996.

Corresponding author: Dr T. L. Pitt. airways secretions are also altered in comparison with normal subjects. In an early study on the composition of mucus from pulmonary secretions, Potter et al. [7] showed a wide spectrum of values for DNA, protein, lipid and carbohydrate in 'normal' (laryngectomised patients), bronchiectatic, and $\mathrm{CF}$ patients; the highest values were found in the CF group. Later, LopezVidreiro and Reid [8] concluded that the quantitative changes in mucus composition were secondary to infection rather than a primary abnormality of the disease. Abnormalities were also described in the ionic composition of CF sputum by Kilbourn [9] who correlated an increased calcium concentration with colonisation by Staphylococcus aureus, and an increased magnesium content with the presence of mucoid $P$. aeruginosa [10].

Given the presence of amino àcid-requiring $P$. aeruginosa variants in $\mathrm{CF}$, it is necessary to show that sputum provides these compound for strains to utilise. Ohman and Chakrabarty [11] studied sputum from two CF patients and suggested that free amino acids were increased in comparison with controls, but they were primarily concerned with the effect of those compounds on alginate production by $P$ aeruginosa. 
In this study, the amino-acid content and profile of $\mathrm{CF}$ sputa were first determined and then the results were compared with those of non-CF specimens.

\section{Materials and methods}

\section{Bacterial isolates}

Thirty-four $P$. aeruginosa isolates were obtained from CF patients and confirmed as auxotrophs for their nutritional status as described previously [6]. $P$. aeruginosa NCTC50184 (met ${ }^{-}$) auxotrophic for methionine was used as a control strain, as well as a prototrophic isolate from a CF patient.

\section{Sputum collection and processing}

Sputum samples from 26 non-CF patients were obtained from the Microbiology Laboratory of The Royal Brompton Hospital, London and from the Department of Microbiology of the Watford General Hospital, London. The information provided on the request form with the sputum was used as clinical data from the non-CF patients. Sputum from $28 \mathrm{CF}$ patients were obtained as described previously [6].

Sputum samples were homogenised by shaking with an equal volume of Ringer's solution and glass beads for c. $3 \mathrm{~min}$. The homogenates were autoclaved at $121^{\circ} \mathrm{C}$ for $15 \mathrm{~min}$ and centrifuged at $11600 \mathrm{~g}$ for $30 \mathrm{~min}$. The supernate (sol phase) was removed and stored at $-20^{\circ} \mathrm{C}$. Sol-phase samples from four patients were subjected to amino-acid determinations before and after autoclaving. Sputum medium was prepared by diluting autoclaved sol-phase sputum extracts 1 in 200 in minimal agar medium (MAM) agar that contained mineral salts and glucose only [12]. The sputum medium plates were inoculated with bacterial suspensions as above and incubated at $37^{\circ} \mathrm{C}$ for $48 \mathrm{~h}$. Plates of King's A agar (KA) [13], MAM without sputum extracts and MAM containing 20 'standard' [14] amino acids plus hydroxyproline and ornithine, each $20 \mu \mathrm{g} / \mathrm{ml}$, were also inoculated as above.

\section{Quantitative determination of amino acids}

All reagents for the determination of amino acids were purchased from Sigma unless otherwise stated. Solphase sputum was assayed for total amino-acid content according to the method of Spies [15] modified by Moore [16]. Briefly, samples were diluted as appropriate and $50 \mu \mathrm{l}$ were mixed with ninhydrin reagent in $4 \times 0.5$-inch tubes with metal caps and placed in a boiling water bath. After $20 \mathrm{~min}$ the tubes were removed from the bath, $0.5 \mathrm{ml}$ of diluent (equal volumes of $n$-propanol and distilled water) was added and left at room temperature for $15 \mathrm{~min}$. The $\mathrm{OD}_{570}$ was read and the amino-acid concentration was calculated with reference to a standard curve for Lleucine.

\section{Thin layer chromatography (TLC) for amino acids}

Volumes of $2 \mu \mathrm{l}$ of sputum sol phase were applied in a $1.5-\mathrm{cm}$ line, $1.5-\mathrm{cm}$ from the bottom of a $10 \times 20-\mathrm{cm}$ cellulose-coated aluminium plate (Merck, Darmstadt, Germany). The solvent used was: N-butanol $35 \mathrm{ml}$, acetone (BDH, Poole) $35 \mathrm{ml}$, glacial acetic acid $(\mathrm{BDH}) 10 \mathrm{ml}$ and distilled water $10 \mathrm{ml}$. The chromatogram was developed twice in the same dimension with the solvent front reaching $7.5 \mathrm{~cm}$ from the origin. Bands corresponding to amino acids were located by spraying the plate with ninhydrin (BDH). A standard solution containing 22 amino acids as above, each at $0.1 \mu \mathrm{g} / \mu \mathrm{l}$, was used as a control. Alternatively, a plate of $20 \times 20 \mathrm{~cm}$ was used to allow longer development (15-cm solvent front) to increase resolution between bands. In this case the concentration of the amino-acid standards was as follows: hydroxyproline, proline and cysteine, $2 \mu \mathrm{g} / \mu \mathrm{l}$; tyrosine, $0.5 \mu \mathrm{g} / \mu \mathrm{l}$; methionine, tryptophan and asparagine, $0.2 \mu \mathrm{g} / \mu \mathrm{l}$, and all other amino acids, $0.1 \mu \mathrm{g} / \mu 1$.

\section{Statistical methods}

The mean values for amino acids in sputum from CF and non-CF patients were compared by the Student's paired and unpaired $t$ tests.

\section{Results}

\section{Quantitative analysis}

The reproducibility of results for total amino-acid content of clinical samples was evaluated. The aminoacid content of 23 sol-phase sputum samples (13 from $\mathrm{CF}$ and 10 from non-CF) was determined on two different occasions. The results were not significantly different $(p=0.7)$; as no quantitative variation in amino acids was detected for the same sample tested on different occasions (Table 1). Sputum samples were also compared for the effect of autoclaving on the amino acid content. Four pairs of samples (before and after autoclaving) were compared and this process did not significantly affect the total amino-acid content $(\mathrm{p}=0.2)($ Table 1$)$.

\section{$C F$ sputum data}

Eighteen of the $28 \mathrm{CF}$ patients were colonised by either auxotrophs alone or both auxotrophic and prototrophic $P$. aeruginosa (Group I). The remainder were either colonised by prototrophic isolates only or not colonised by $P$. aeruginosa (Group II) (Table 2 ). In general, patients colonised with auxotrophic $P$. aeruginosa had a higher sputum amino-acid content with a mean of $6.77 \mathrm{mg} / \mathrm{ml}$ (range 0.96-14.30) compared with Group II which had a mean value of $3.77 \mathrm{mg} / \mathrm{ml}$ (range 1.32-10.66) $(\mathrm{p}=0.0167)$. Sixteen $(89 \%)$ of the patients in Group I had sputum amino-acid levels of $>4 \mathrm{mg} / \mathrm{ml}$ compared with only two patients $(20 \%)$ 
Table 1. Reproducibility and effect of autoclaving on the quantitative determination of amino acids in sputum samples

\begin{tabular}{|c|c|c|c|c|c|}
\hline \multirow{2}{*}{$\begin{array}{l}\mathrm{CF} \\
\text { patient } \\
\text { no. }\end{array}$} & \multicolumn{2}{|c|}{ Amino-acid content $(\mathrm{mg} / \mathrm{ml})$} & \multirow{2}{*}{$\begin{array}{l}\text { Non-CF } \\
\text { patient } \\
\text { no. }\end{array}$} & \multicolumn{2}{|c|}{ Amino-acid content $(\mathrm{mg} / \mathrm{ml})$} \\
\hline & D1 & D2 & & D1 & D2 \\
\hline 2 & 0.98 & 0.94 & 1 & 1.26 & 1.58 \\
\hline 4 & 9.48 & 9.26 & 2 & 1.48 & 1.48 \\
\hline 6 & 6.48 & 5.80 & 4 & 3.04 & 2.34 \\
\hline 13 & 7.14 & 7.96 & 8 & 1.02 & 0.84 \\
\hline 15 & 6.18 & 5.96 & 9 & 1.92 & 1.52 \\
\hline 17 & 4.20 & 4.28 & 10 & 1.60 & 1.42 \\
\hline 34 & 15.26 & 13.40 & 21 & 0.82 & 0.80 \\
\hline 37 & 8.76 & 9.36 & 23 & 0.40 & 0.38 \\
\hline 51 & 10.70 & 11.20 & 25 & 1.92 & 2.08 \\
\hline 47 & 6.90 & 7.32 & 26 & 9.06 & 9.66 \\
\hline 39 & 2.93 & 2.54 & & & \\
\hline 48 & 1.76 & 1.74 & $\mathrm{D} l v s \mathrm{D}$ & $\mathrm{p}=\mathrm{c}$ & \\
\hline \multirow[t]{2}{*}{23} & 0.69 & 0.77 & & & \\
\hline & \multicolumn{5}{|c|}{ Amino-acid content $(\mathrm{mg} / \mathrm{ml})$} \\
\hline Sample & \multicolumn{2}{|c|}{ before autoclaving } & \multicolumn{3}{|c|}{ after autoclaving } \\
\hline A & 1.36 & \multirow{4}{*}{$\mathrm{p}=0.2^{*}$} & \multicolumn{2}{|c|}{1.26} & \\
\hline B & 3.24 & & \multicolumn{2}{|c|}{3.04} & \\
\hline $\mathrm{C}$ & 9.96 & & \multicolumn{2}{|c|}{9.20} & \\
\hline D & 1.60 & & \multicolumn{2}{|c|}{1.60} & \\
\hline
\end{tabular}

D1, first determination; D2, second determination.

${ }^{*}$ Not significant (paired $t$ test).

Table 2. Amino-acid content of sputum extracts from CF patients

\begin{tabular}{llr}
\hline $\begin{array}{l}\text { Patient } \\
\text { no. }\end{array}$ & $\begin{array}{l}\text { Nutritional status of } P \text { aeruginosa } \\
\text { (amino-acid requirement) }\end{array}$ & Amino-acid content $(\mathrm{mg} / \mathrm{ml})$ \\
\hline Group I & & \\
2 & PRO and AUX (met) & 0.96 \\
4 & PRO and AUX (ser) & 9.37 \\
6 & PRO and AUX (met) & 6.14 \\
7 & PRO and AUX (met) & 4.20 \\
9 & PRO and AUX (NI) & 1.46 \\
13 & PRO and AUX (leu) & 7.55 \\
15 & PRO and AUX (his) & 6.07 \\
17 & PRO and AUX (arg) & 4.24 \\
18 & PRO and AUX (arg) & 6.12 \\
24 & PRO and AUX (NI) & 6.40 \\
28 & PRO and AUX (met) & 8.50 \\
30 & PRO and AUX (ile \& val) & 6.60 \\
34 & PRO and AUX (trp) & 14.30 \\
37 & PRO and AUX (met) & 9.06 \\
38 & PRO and AUX (met) & 6.76 \\
47 & AUX (met) & 7.11 \\
49 & PRO and AUX (met) & 6.10 \\
51 & PRO and AUX (met) & 10.95 \\
Group II & & \\
1 & PRO & 3.06 \\
3 & PRO & 3.86 \\
5 & PRO & 1.32 \\
8 & PN & 10.60 \\
10 & PRO & 5.00 \\
29 & PN & 2.64 \\
32 & PN & 2.73 \\
39 & PRO & 1.75 \\
48 & PRO & 3.44 \\
52 & PN & \\
\hline
\end{tabular}

PRO, prototroph; AUX, auxotroph; NI, not identified; PN, culture negative for $P$. aeruginosa. ${ }^{*}$ Group I, patients colonised by either auxotrophs alone or both auxotrophic and prototrophic $P$. aeruginosa; Group II, patients colonised by prototrophic isolates only, or not colonised by $P$. aeruginosa. 
from Group II. However, the CF sputum specimen with the lowest amino-acid content $(0.96 \mathrm{mg} / \mathrm{ml})$ originated from a patient who harboured both auxotrophic and prototrophic isolates.

\section{$C F$ versus non- $C F$ specimens}

The amino-acid content of sputum sol-phase extracts of the $28 \mathrm{CF}$ patients was compared with values for sputum extracts of 26 non-CF patients given in Table 3. The mean amino-acid content for $\mathrm{CF}$ and non-CF specimens was $5.70 \mathrm{mg} / \mathrm{ml}$ (range 0.96-14.33) and $2.52 \mathrm{mg} / \mathrm{ml}$ (range 0.39-9.36) $(\mathrm{p}=0.0002)$ respectively. Twenty-two (79\%) of CF specimens contained $>3 \mathrm{mg}$ of amino acids $/ \mathrm{ml}$ compared with only $4(15 \%)$ on non-CF specimens (Fig. 1).

Individual comparisons of amino-acid content of the CF Groups I and II with the values for the 26 non-CF patients were made. Although the amino-acid values of CF Group I were significantly higher than for the non-CF population $(p<0.0001)$ there was no difference between the CF Group II and the non-CF population $(\mathrm{p}=0.1979)$ (Table 4).

\section{Qualitative analysis by TLC}

To identify the profile of individual amino acids all sputum samples were examined by one-dimensional TLC on a $10 \mathrm{~cm} \times 20 \mathrm{~cm}$ plate. Each of the 28 solphase extracts from CF patients gave a complex but relatively constant amino-acid profile that varied only in the intensity of bands which appeared to correlate with the total amino-acid content (Fig. 2). The profiles were similar to those given by non-CF specimens that contained sufficient amino acids detectable by chromatography and they generally corresponded to the 22 amino acids standard, but it was difficult to identify precisely individual amino acids in each profile.

The presence of individual amino acids did not appear to be influenced by autoclaving, as the one-dimensional TLC profiles of four pairs of sputum pre- and post-autoclaving were indistinguishable.

The resolution between amino-acid bands in a sample from a CF patient was increased by the use of a $20 \mathrm{~cm} \times 20 \mathrm{~cm}$ plate in one-dimensional TLC. Fig. 3 shows that the longer development for the migration of individual bands could be correlated more precisely with the bands of standard amino acids contained in the control pools. A single band related to each amino acid was visualised in the standards, although some compounds, particularly lysine and arginine, had a more diffuse migration pattern than others. It was also found that for most amino acids a concentration of $0.1 \mu \mathrm{g} / \mu \mathrm{l}$ (final amount per lane of $2 \mu \mathrm{g}$ ) was sufficient to render bands visible in the chromatogram. The exceptions were hydroxyproline, proline, cysteine, tyrosine, methionine, tryptophan and asparagine, which yielded weaker bands at $0.1 \mu \mathrm{g} / \mu \mathrm{l}$. To circumvent this problem, higher concentrations of

Table 3. Amino-acid content and clinical data of non-CF patients

\begin{tabular}{|c|c|c|c|}
\hline $\begin{array}{l}\text { Patient } \\
\text { no. }\end{array}$ & Culture & Clinical information & $\begin{array}{c}\text { Amino-acid content } \\
(\mathrm{mg} / \mathrm{ml})\end{array}$ \\
\hline 1 & No significant growth & Bronchiectasis & 1.42 \\
\hline 2 & No significant growth & Carcinoma & 1.48 \\
\hline 3 & Haemophilus influenzae & Bronchiectasis & 1.48 \\
\hline 4 & No significant growth & Upper respiratory tract infection & 2.69 \\
\hline 5 & $P$ aeruginosa & Asthma & 1.00 \\
\hline 6 & No significant growth & Not supplied & 0.98 \\
\hline 7 & Branhamella catarrhalis & Asthma & 9.20 \\
\hline 8 & No significant growth & Not supplied & 0.93 \\
\hline 9 & B. catarrhalis & Heart failure/Chest infection & 1.72 \\
\hline 10 & Pseudomonas sp. & Bronchiectasis & 1.51 \\
\hline 11 & No significant growth & Coronary artery by-pass graft & 2.90 \\
\hline 12 & No significant growth & Carcinoma of the lung & 1.66 \\
\hline 13 & $H$. influenzae & Not supplied & 1.64 \\
\hline 14 & $P$ aeruginosa (mucoid) & Bronchiectasis & 1.28 \\
\hline 15 & No significant growth & Not supplied & 1.20 \\
\hline 16 & B. catarrhalis & Asthma & 3.60 \\
\hline 17 & $H$. influenzae & Not supplied & 1.64 \\
\hline 18 & $P$ aeruginosa & Bronchiectasis & 8.96 \\
\hline 19 & No significant growth & Post coronary artery by-pass & 1.80 \\
\hline 20 & No significant growth & Bronchiectasis & 2.48 \\
\hline 21 & No significant growth & Right lower lobe pneumonia & 0.81 \\
\hline 22 & Streptococcus pneumoniae + normal flora & Clot retention & 1.16 \\
\hline 23 & No significant growth & Persistent cough sputum & 0.39 \\
\hline 24 & Pseudomonas sp. + normal flora & Cough sputum & 2.24 \\
\hline 25 & $H$. influenzae & Infective pleurisy & 2.00 \\
\hline 26 & Staphylococcus aureus & Atrial fibrillation/Chest infection & 9.36 \\
\hline
\end{tabular}




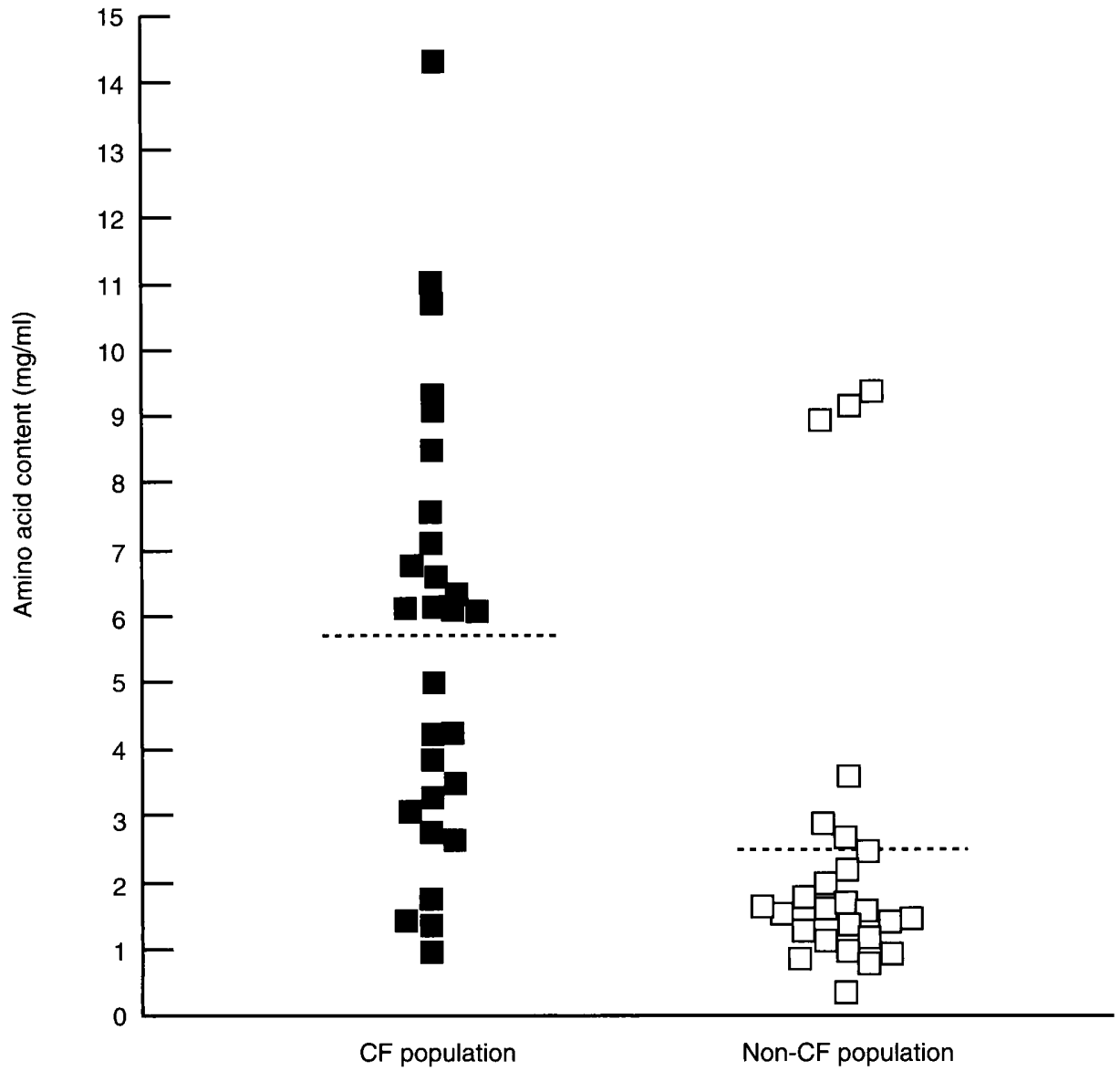

Fig. 1. Distribution of amino-acid content of $C F$ and non-CF sputum samples; - - - mean.

Table 4. Summary of amino-acid content of sputum specimens from CF and non-CF populations

\begin{tabular}{lcccc}
\hline $\begin{array}{l}\text { Patient } \\
\text { group }\end{array}$ & $\begin{array}{c}\text { Number } \\
\text { of } \\
\text { samples }\end{array}$ & $\begin{array}{c}\text { Mean amino- } \\
\text { acid content } \\
(\mathrm{mg} / \mathrm{ml})\end{array}$ & $\begin{array}{c}\text { Minimum } \\
\text { value }\end{array}$ & $\begin{array}{c}\text { Maximum } \\
\text { value }\end{array}$ \\
\hline CF Group I* & 18 & 6.77 & 0.96 & 14.30 \\
CF Group II & 10 & 3.78 & 1.32 & 10.66 \\
CF (Total) & 28 & 5.70 & 0.96 & 14.30 \\
Non-CF & 26 & 2.52 & 0.39 & 9.36 \\
\hline
\end{tabular}

* See Table 1.

Associations (unpaired $t$ test)

CF Group I vs CF Group II $\mathrm{p}=0.0167$ significant

$\mathrm{CF}$ (Total) vs Non-CF $\mathrm{p}=0.0002$ highly significant

CF Group I vs Non-CF $\mathrm{p}<0.0001$ highly significant

CF Group II vs Non-CF $\mathrm{p}=0.1979$ not significant

these compounds were used (see Materials and methods).

The purple colour developed by bands after location with ninhydrin spray was similar for all amino acids with the exception of bands formed by the imino acids (hydroxyproline and proline), and asparagine which gave a yellow and brown colour, respectively. Some amino acids may generate spots associated with secondary compounds and this was particularly evident for cysteine, an amino acid which degrades rapidly into autoxidation products (Fig. 3).

Amino acids such as leucine, isoleucine, phenylalanine, tyrosine, alanine, threonine and serine were readily identified by the unique position of their bands. However, a number of bands in the sputum profile may represent multiple amino acids, as some compounds had the same or very similar rates of migration. This was the case for methionine and 


\section{Amino acids}

control

CF sputum extracts

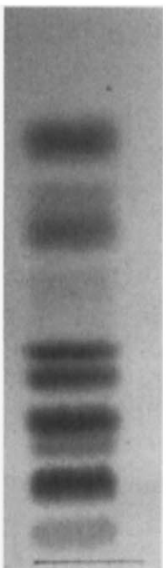

Patient no. 2

Total amino acid

content (mg/ml)

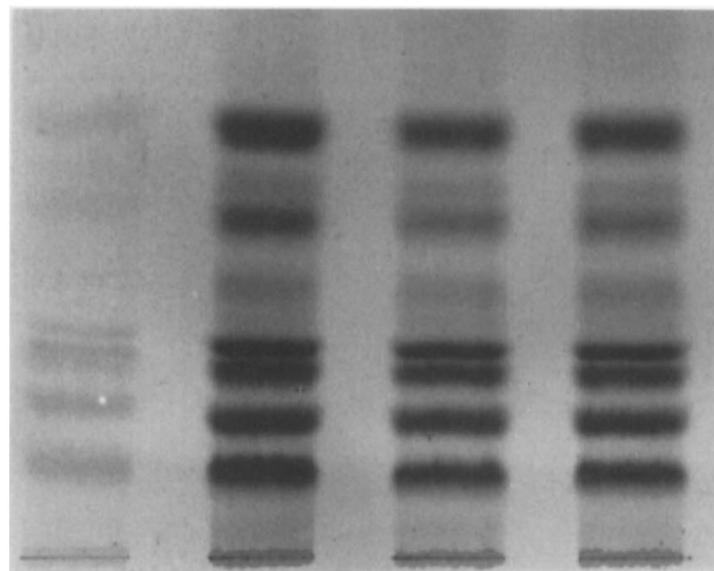

13
Non-CF sputum extracts

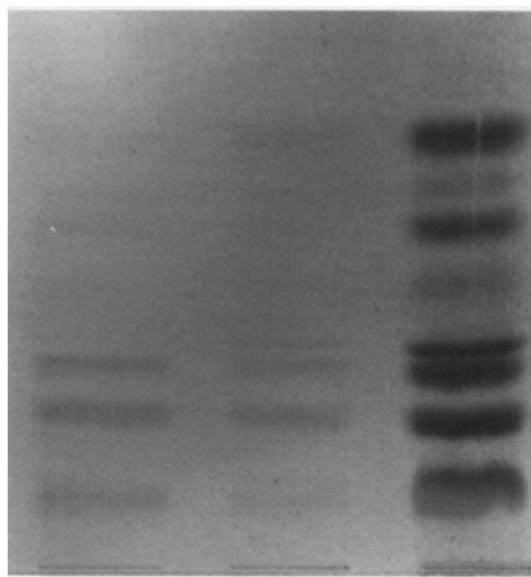

5

6

7

Fig. 2. One-dimensional TLC of sputum extracts from selected CF and non-CF patients and amino-acid standards.

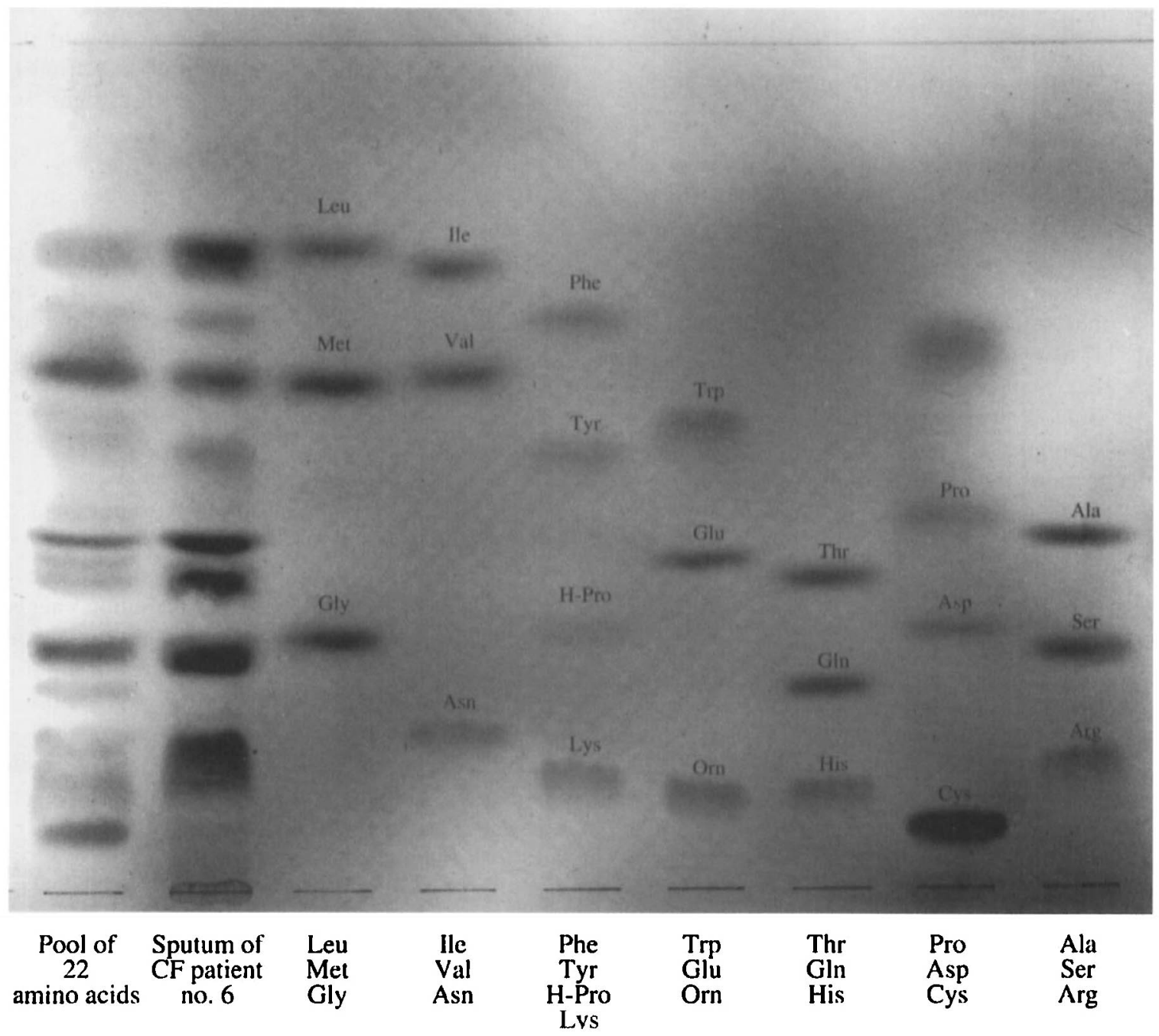

Fig. 3. One-dimensional TLC of a sputum extract from a CF patient and the correlation of bands with those of aminoacid pools. Individual compounds are given in vertical order according to position of bands. The most rapidly migrating spot in the complex of proline/aspartic acid/cysteine is believed to be a degradation product of cysteine. 
valine, glycine and hydroxyproline, and the least mobile complex of asparagine-arginine-lysine-ornithine-histidine. Some compounds - namely, tryptophan, proline, glutamic acid, glutamine, cysteine and aspartic acid - were not visible in the profiles generated from sputum extracts. There were also two bands in the sputum profile that did not correlate with any of the amino acid standards: a yellow spot immediately above the band associated with threonine and a dense band just below that of serine. A difference in the intensity of bands formed by individual amino acids in the sputum profiles was observed. Bands related to leucine, isoleucine, alanine and serine were slightly stronger than most of the others and probably indicated a higher concentration of these compounds in the sputum.

Two-dimensional TLC did not markedly improve resolution between amino acids over the one-dimensional technique, as there was a significant margin of variation in the relative mobilities of amino acids in different chromatographic runs (data not shown). Nevertheless, the latter did confirm the basic aminoacid constitution of the profile obtained with the onedimensional technique.

\section{Sputum extracts as source of nutrients}

Sol-phase extracts of sputum from 22 of $28 \mathrm{CF}$ patients, and six from the non-CF patients were each incorporated into MAM and tested as substrates for the growth of a panel of 34 auxotrophs which required single or multiple amino acids for growth (Table 5). All CF sputum specimens supported the growth of each of the strains with the exception of that from patient 24 that failed to promote the growth of a single strain that required serine or glycine. Apart from 10 isolates, which were not tested against their sputum of origin, all grew on MAM supplemented with the sputum from which they were isolated. Strain NCTC 50184, auxotrophic for methionine, also grew

Table 5. Amino-acid requirements of auxotrophic $P$. aeruginosa isolates tested for growth on MAM supplemented with sputum extracts

\begin{tabular}{lc}
\hline Requirement & $\begin{array}{c}\text { Number of isolates } \\
(\mathrm{n}=34)\end{array}$ \\
\hline Methionine & 18 \\
Isoleucine and valine & 3 \\
Leucine & 2 \\
Arginine or ornithine & 2 \\
Histidine & 1 \\
Serine or glycine & 1 \\
lsoleucine and valine and leucine & 1 \\
Tryptophan & 1 \\
Methionine and leucine & 1 \\
Aspartic acid or arginine & 1 \\
Lysine & 1 \\
Lysine and methionine & 1 \\
Histidine and methionine & 1 \\
\hline
\end{tabular}

on all CF sputum media as did the prototrophic control from a CF patient.

The growth of isolates on sputum medium was compared with the growth on MAM containing 22 amino acids. The growth on the majority of individual CF sputum extracts was equivalent, although less intense, to the growth on the pool of amino acids (Fig. 4). Growth was poorest on CF sputum extracts with lower amino-acid content. This was particularly evident for the extracts from CF patients 2 and 9 , which had very low amino-acid concentrations $(<1.5 \mathrm{mg} / \mathrm{ml})$. The latter were variable in their ability to support the growth of auxotrophs; some isolates grew more luxuriantly than others but, overall, most grew poorly in comparison with MAM supplemented with other sputum or amino-acids pool. It was also observed that some isolates produced more mucoid growth on MAM plus amino acids than on KA.

With the exception of the sputum extract from patient 7 , which promoted exuberant growth of all the auxotrophs, the other five specimens tested from non-CF patients (nos. 1, 2, 4, 8 and 9) supported only very poor or no growth of the isolates. Here again, the growth of auxotrophs was associated with a high amino-acid content in the samples.

It is noteworthy that of the $34 \mathrm{CF}$ isolates, one grew as mucoid colonies only on $\mathrm{KA}$, two isolates were mucoid on both KA and MAM containing 22 amino acids, and five had the mucoid characteristic evident only on MAM containing amino acids. Four of the latter required methionine for growth.

\section{Discussion}

There are conflicting views as to the nutritional status of the sputum of CF patients. Ohman and Chrakrabarty [11] showed that two CF patients' sputa had relatively high concentrations of total amino acids and contained a range of nutrients necessary to support the growth and production of large amounts of alginate by $P$. aeruginosa, but Speert et al. [17] postulated, without sputum analysis, that $P$. aeruginosa grew under energy-limiting conditions in the CF bronchopulmonary milieu and it was this starvation of nutrients that led to the mutation to mucoidy and loss of $\mathrm{O}$ antigen by strains.

Although rare in other diseases, auxotrophy is a common phenomenon among bacteria colonising CF patients $[5,18,19]$. Earlier studies demonstrated that the auxotrophic variants of $P$. aeruginosa and Burkholderia cepacia were derived from the prototrophic wild-type strains $[6,19]$ but the mechanism of selection of these forms in vivo remains obscure. The 

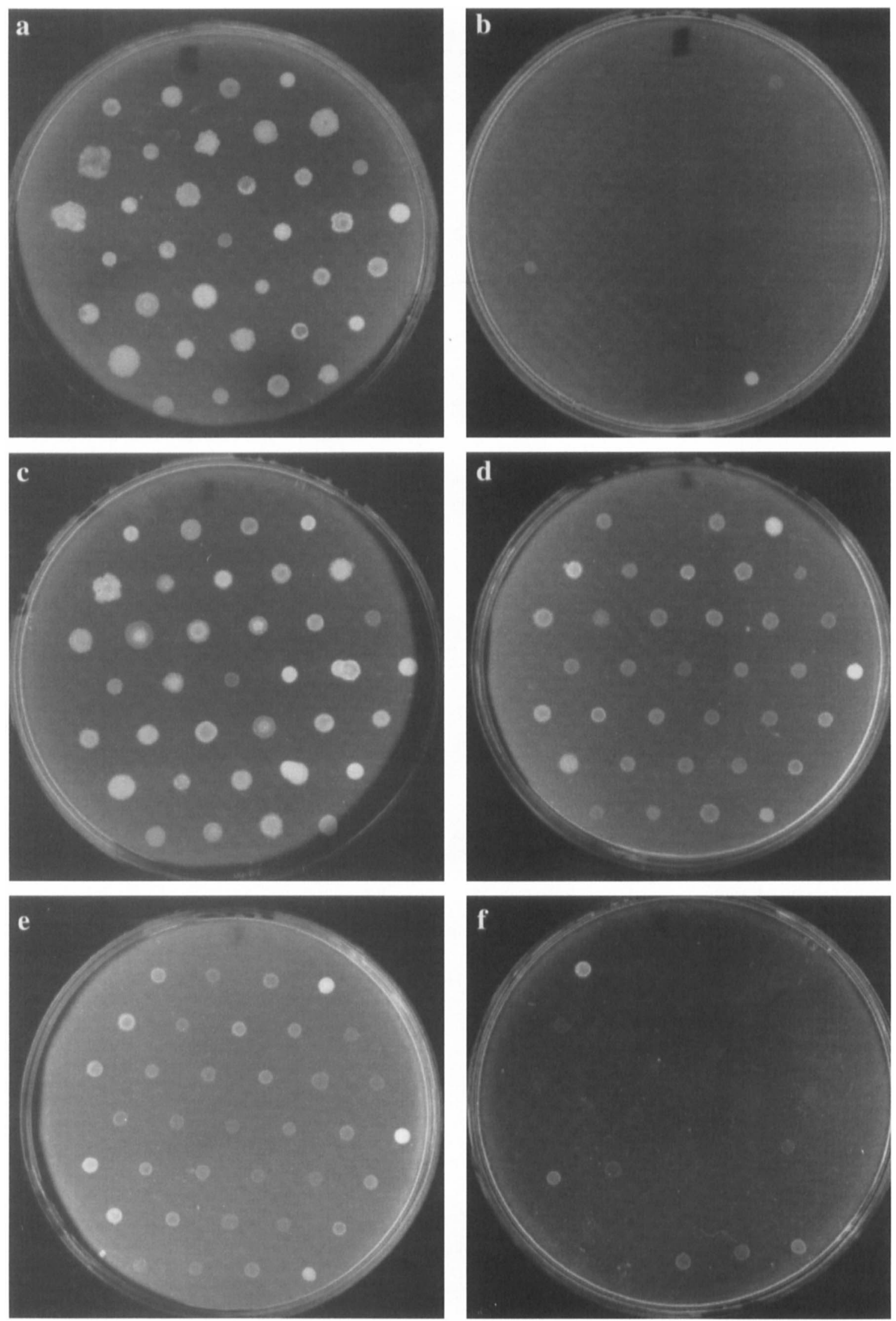

Fig. 4. Growth of 34 auxotrophic P. aeruginosa isolates from CF and two control strains on: a, KA; b, MAM; c, MAM supplemented with 22 amino acids; d, MAM plus sputum extract from patient no. 24 (amino-acid content $6.4 \mathrm{mg} / \mathrm{ml}$ ); e, MAM plus sputum extract from patient no. $34(14.30 \mathrm{mg} / \mathrm{ml}) ;$ f, MAM plus sputum extract from patient no. 9 $(1.46 \mathrm{mg} / \mathrm{ml})$. 
present study showed unequivocally that $\mathrm{CF}$ sputum contains quantitatively more amino acids than non-CF specimens. Indeed, the presence of several individual amino acids was demonstrated by TLC. Furthermore, each of 22 sputum extracts from CF patients with amino-acid content $>1.5 \mathrm{mg} / \mathrm{ml}$ promoted the growth of virtually all auxotrophic $P$. aeruginosa tested.

The determination of total amino acids with ninhydrin may be subject to chemical interference and therefore absolute values in sputum may vary. However, the aim was to compare the amino-acid content of CF and non-CF specimens and it was reasoned that any interference in the reaction of ninhydrin with $\mathrm{NH}_{2}$ groups would be similar in both groups of specimens. It was also the case that a precise determination of the presence or absence of some amino acids was not achievable with TLC, but ready access to more sophisticated amino-acid analysis was not available.

The lack of growth of auxotrophic $P$. aeruginosa in sputum extracts, either of CF or non-CF origin, was associated with a lower content of total amino acids, indicating that these compounds need to be present in at least minimal amounts to support the growth of nutritionally deficient $P$. aeruginosa. Furthermore, amino acids may play an important role in cellular growth rate and alginate production by mucoid $P$. aeruginosa, as reduced growth and decrease in alginate yields was correlated with the removal of amino acids and small peptides from sputum [11] This study showed that some auxotrophic strains were clearly mucoid only in media supplemented with a pool of amino acids.

It is possible that the excess of free amino acids in the lung of CF patients provides conditions in which mutations of strains leading to nutritional deficiency, a putative disadvantage in a natural environment, may not be a significant handicap in comparison with nutritionally sufficient prototrophs. This was first raised by Lwoff (cited in Harder and Kuenen [20]) who, in a study on the establishment of parasitism, suggested that auxotrophic mutants had a selective advantage over prototrophic forms due to energetic economy. The production of certain amino acids by bacteria is an energetically expensive process [21], thus cells that take up these compounds from the external environment may be able to conserve energy. Interestingly, the mutation leading to the non-motile phenotype characteristic of CF $P$. aeruginosa isolates was associated with glutamine auxotrophy and thought to be an adaptive response by the bacterium to conserve energy [22].

Similarly, it is noteworthy that strains bearing the metBI mutation, which causes a requirement for methionine in Escherichia coli, revert to prototrophy under conditions of methionine starvation at rates 80 fold higher in aged colonies than for growing cultures
[23]. If this can be applied to the situation in vivo, one may postulate that the increased free amino acids in the CF airways would be a key factor for the selection and maintenance of auxotrophic forms colonising these patients.

The phenomenon of auxotrophy is relatively uncommon in wild-type bacteria causing infections, but $c$. $1.5 \%$ of $E$. coli isolates from urinary tract infection are auxotrophic for cysteine [24] and this is associated with an accumulation of cysteine-homocysteine in vivo in patients with decreased renal function [25]. Furthermore, the selection of cysteine-requiring $E$. coli from prototrophic forms in vitro was demonstrated to be enhanced by an excess of cysteine and other sulphur compounds [26].

The origin of free amino acids in the sputum of CF patients is not clear. These compounds may be direct exoproducts from the bacterium itself or from its interaction with the host. The release of free amino acid to the external environment by actively growing prototrophic $P$. aeruginosa was not detected. However, preliminary experiments on satellitism between prototrophs and auxotrophs indicate that a minority of prototrophs do produce substances that can support the growth of some nutritionally deficient strains of $P$. aeruginosa (data not shown). The increased levels of amino acids in the CF airways may, therefore, be associated with the action of bacterial exogenous proteases on the human cells or to the inflammatory response of the host, or both. Indeed, Cicmanec and Holder [27] proposed that the role of exoproteases from $P$. aeruginosa is to generate more utilisable nutritional substrates, such as amino acids, that would facilitate the growth of the bacterium to the levels required for systemic invasion.

We propose that $P$. aeruginosa in CF grows in a pool of amino acids and that this selects and perpetuates the state of auxotrophy as a direct response to the amino-acid rich environmental challenge.

A.L.B. was supported by a grant from Conselho Nacional de Desenvolvimento Científico e Tecnológico $(\mathrm{CNPq})$, Brazil. We thank Dr H. Gaya and P. Webber (Microbiology Department, Royal Brompton Hospital, London) for supplying sputum and bacteriological information.

\section{References}

1. Govan JRW, Glass S. The microbiology and therapy of cystic fibrosis lung infections. Rev Med Microbiol 1990; 1: 19-28.

2. Govan JRW. Mucoid strains of Pseudomonas aeruginosa: the influence of culture medium on the stability of mucus production. J Med Microbiol 1975; 8: 513-522.

3. Hancock REW, Mutharia LM, Chan L, Darveau RP, Speert DP, Pier GB. Pseudomonas aeruginosa isolates from patients with cystic fibrosis: a class of serum-sensitive, nontypable strains deficient in lipopolysaccharide $\mathrm{O}$ side chains. Infect Immun 1983; 42: $170-177$.

4. Irvin RT, Govan JRW, Fyfe JAM, Costerton JW. Heterogeneity of antibiotic resistance in mucoid isolates of Pseudomonas 
aeruginosa obtained from cystic fibrosis patients: role of outer membrane proteins. Antimicrob Agents Chemother 1981; 19. $1056-1063$

5. Taylor RFH, Hodson ME, Pitt TL. Auxotrophy of Pseudomonas aeruginosa in cystic fibrosis. FEMS Microbiol Lett 1992; 92: 243-246.

6. Barth AL, Pitt TL. Auxotrophic variants of Pseudomonas aeruginosa are selected from prototrophic wild-type strains in respiratory tract infections in patients with cystic fibrosis. $J$ Clin Microbiol 1995; 33: 37-40.

7. Potter JL, Matthews LW, Lemm J, Spector S. Human pulmonary secretions in health and disease. Ann NY Acad Sci 1963; 106: 692-697.

8. Lopez-Vidriero MT, Reid L. Bronchial mucus in health and disease. Br Med Bull 1978; 34: 63-74.

9. Kilbourn JP. Bacterial content and ionic composition of sputum in cystic fibrosis. Lancet 1978; 1: 334.

10. Kilbourn JP. Biochemical abnormalities in sputum from cystic fibrosis patients possibly enhancing lung infection. Clin Chem 1984; 30: 946-947.

11. Ohman DE, Chakrabarty AM. Utilization of human respiratory secretions by mucoid Pseudomonas aeruginosa of cystic fibrosis origin. Infect Immun 1982; 37: 662-669.

12. Clowes RC, Hayes W. (eds) Experiments in microbial genetics Oxford, Blackwell Scientific Publications. 1968: 184-185.

13. King EO, Ward MK, Raney DE. Two simple media for the demonstration of pyocyanin and fluorescein. $J$ Lab Clin Med 1954; 44: 301-307.

14. Voet D, Voet JG. Biochemistry. New York, John Wiley and Sons. 1990: 59-74.

15. Spies JR. Colorimetric procedures for amino acids. Methods Enzymol 1957; 3: 467-477.

16. Moore S. Amino acid analysis: aqueous dimethyl sulfoxide as solvent for the ninhydrin reaction. $J$ Biol Chem 1968; 243 $6281-6283$

17. Speert DP, Farmer SW, Campbell ME, Musser JM, Selander
RK, Kuo S. Conversion of Pseudomonas aeruginosa to the phenotype characteristic of strains from patients with cystic fibrosis. J Clin Microbiol 1990; 28: 188-194.

18. Gilligan PH, Gage PA, Welch DF, Muszynski MJ, Wait KR Prevalence of thymidine-dependent Staphylococcus aureus in patients with cystic fibrosis. J Clin Microbiol 1987; 25: $1258-1261$

19. Barth AL, Pitt TL. Auxotrophy in Burkholderia (Pseudomonas) cepacia from cystic fibrosis patients. J Clin Microbio 1995; 33: 2192-2194.

20. Harder W, Kuenen JG, Matin A. A review. Microbial selection in continuous culture. $J$ Appl Bacteriol 1977; 43: 1-24.

21. Old IG, Phillips SEV, Stockley PG, Saint-Girons I. Regulation of methionine biosynthesis in the Enterobacteriaceae. Prog Biophys Mol Biol 1991; 56: 145-185.

22. Mahenthiralingam E, Campbell ME, Speert DP. Nonmotility and phagocytic resistance of Pseudomonas aeruginosa isolates from chronically colonized patients with cystic fibrosis. Infect Immun 1994; 62: 596-605.

23. Hall BG. Selection, adaptation, and bacterial operons. Genome 1989; 31: 265-271.

24. Borderon E, Horodniceanu T. Metabolically deficient dwarfcolony mutants of Escherichia coli: deficiency and resistance to antibiotics of strains isolated from urine culture. $J$ Clin Microbiol 1978; 8: 629-634.

25. Wilcken DEL, Grupta VJ, Reddy SG. Accumulation of sulphur-containing amino acids including cysteine-homocysteine in patients on maintenance haemodialysis. Clin Sci 1980; 58: $427-430$.

26. McIver CJ, Tapsall JW. Further studies of clinical isolates of cysteine-requiring Escherichia coli and Klebsiella and possible mechanisms for their selection in vivo. $J$ Med Microbiol 1993; 39: $382-387$

27. Cicmanec JF, Holder IA. Growth of Pseudomonas aeruginosa in normal and burned skin extract: role of extracellular proteases. Infect Immun 1979; 25: 477-483. 